\title{
A CRIANÇA, A MÃE SOCIAL E O ABRIGO: LIMITES E POSSIBILIDADES ${ }^{\#}$
}

\author{
THE CHILD, THE SOCIAL MOTHER AND THE ORPHANAGE: \\ LIMITATIONS AND POSSIBILITIES
}

Paula Cristina Nogueira*

Liana Fortunato Costa**

\begin{abstract}
Nogueira PC, Costa LF. A criança, a mãe social e o abrigo: limites e possibilidades. Rev Bras Cresc Desenv Hum 2005; 15(3):36-48.

Resumo: Esse trabalho pretende elaborar reflexões acerca da realidade das crianças que se encontram em situação de abrigamento, buscando compreender a função do educador neste contexto. Para tanto desenvolvemos uma pesquisa qualitativa e em uma instituição que recebe e acolhe crianças no período de zero a três anos de idade, que ficam sob a responsabilidade de uma mãe social. O lar social estudado contava com 12 crianças e 4 adolescentes, sendo um deles filho biológico da mãe social. Utilizamos a etnometodologia, num total de seis observações, sobre a rotina de cuidados, sobre momentos de brincadeiras das crianças e sobre o momento da alimentação e da hora de dormir. As observações nos levaram a concluir que a qualificação das mães sociais seria o aspecto mais importante a ser observado para o oferecimento de cuidados adequados às crianças que permanecem em situação de abrigamento.
\end{abstract}

Palavras chave: Criança institucionalizada. Abrigo. Mãe social.

\section{INTRODUÇÃO}

A relação mãe-bebê e a importância dos primeiros anos de vida para a estruturação psíquica a criança vem se tornando, ao longo dos anos, alvo de discussões e estudos significativos e relevantes ${ }^{1-5}$. Nesse sentido, compreende-se o valor significativo (ou a importância) de estudos que discutem e aprofundam questões relacionadas à separação da criança do contato materno ${ }^{6-9}$.

Como conseqüência da separação, o que se observa é a necessidade de se colocar a criança em instituições de abrigamento, responsáveis pelo acolhimento e cuidado de crianças que, por inúmeras razões, precisaram ser afastadas de suas famílias de origem. Fundamental mencionar, entretanto, que a institucionalização, que acaba sendo a conseqüência da separação, apesar de muitas vezes necessária, é uma prática que deve ser pensada com cuidado. A separação da mãe pode provocar cicatrizes emocionais extremamente profundas. "Sem dúvida, a privação materna nos

\footnotetext{
Esse artigo está baseado na Dissertação de Mestrado “A criança em situação de abrigamento: reparação ou reabandono?" defendida em dezembro de 2004, perante o Departamento de Psicologia Clínica do Instituto de Psicologia da Universidade de Brasília, realizada pela primeira autora sob a orientação da segunda. Apoio da CAPES.

* Psicóloga, Mestre em Psicologia Clínica pela Universidade de Brasília, Professora do Curso de Psicologia da Univer sidade Paulista - UNIP/DF Endereço: SQN 106, Bloco E ap. 504 Brasília - DF - 70742-050 Telefones: 61327226 80/ 6181196106 E-mail: paulanogueira@ hotmail.com

** Psicóloga, Terapeuta Familiar, Psicodramatista Doutora em Psicologia Clínica pela Universidade de São Paulo. Do cente Permanente do Departamento de Psicologia Clínica do Instituto de Psicologia da Universidade de Brasília SQN 104 Bloco D ap. 307 Brasília - DF - 70733040 Tel: (61) 3328-7439 Fax: (61) 3326-9710 E-mail: lianaf@terra.com.br 
primeiros anos de vida tem sido comparada a uma queimadura profunda. A dor é inimaginável. A cicatrização é difícil e lenta. O dano, apesar de não ser fatal, pode ser permanente" (Viorst, 1986 apud $^{9}$, p. 40).

As crianças que se encontram em abrigos (aguardando adoção ou o retorno para suas famílias de origem) são provenientes de várias situações estressantes: agressão, violência física e psíquica, privações variadas, abuso sexual, tudo isso somado à necessidade de terem sido retiradas do contato com suas famílias de origens. Quando se entra em contato com a dinâmica da instituição que as acolhe, compreende-se a importância de se discutir a função dessas instituições de abrigamento, uma vez que se reconhecem as dificuldades implicadas na separação mãe-criança e, consequientemente, as limitações dos cuidados oferecidos por pessoas com quem a criança não tenha laços afetivos profundos.

Ao pensarmos na dinâmica da criança dentro da instituição, é inegável o fato de que o profissional responsável pelo cuidado é quem a acompanha, permitindo que ela seja capaz de falar sobre si, através de brincadeiras (no caso de crianças pequenas), ações e diálogos. Sendo assim, esses profissionais têm papel e função fundamentais dentro da instituição, pois lidam diretamente com as crianças, estão mais próximos, acompanham o desenvolvimento e aquisições de cada criança de forma mais direta e permanente $\mathrm{e}^{10-12}$.

Nesse trabalho pretendemos aprofundar nossas reflexões acerca da realidade das crianças que se encontram em situação de abrigamento, buscando compreender a função do cuidador neste contexto. Para tanto, desenvolvemos uma pesquisa qualitativa e em uma instituição que recebe e acolhe crianças no período de zero a três anos de idade. Nesta instituição, o cuidador recebe a denominação de mãe social - denominação esta que será adotada ao longo do texto.

\section{A mãe social: profissão e função materna}

No estudo da rotina de abrigos, é preciso considerar algumas características recorrentes que fazem parte do dia-a-dia dessas instituições. Dentre tais características, podemos citar: cuidados pouco atentos às manifestações das crianças, tratamento sempre voltado para a coletividade, além da alta rotatividade dos profissionais da instituição, que ficam no trabalho por poucos meses sendo, constantemente, substituídos e remanejados, o que acaba, inevitavelmente, por reeditar a experiência de separação vivenciada pela criança não só relação à sua mãe e à sua família, mas também pelas profissionais responsáveis por elas quando institucionalizadas. Para Winnicott ${ }^{13}$, em um contexto institucional, pessoas, mesmo que excelentes, mas que logo deixam o trabalho junto às crianças, são consideradas um mal. Afinal, "é a natureza permanente do lar que o torna valioso, mais do que o fato do trabalho ser realizado com inteligência" (p. 77). O autor afirma ainda que a inadequação da equipe de trabalho, responsável pelas crianças, pode acarretar problemas de saúde e colapso entre os próprios membros, afetando as relações, assim como a continuidade do trabalho, o que é essencial nesse tipo de contato com crianças.

Com base nessas constatações, pensamos que o papel da mãe social tem importância fundamental na dinâmica da instituição. Assim, o objeto deste estudo será a relação estabelecida entre a criança e a mãe social, com o objetivo de se propor alternativas de trabalho e de preparo desses profissionais que desempenham papel tão importante na formação dessas crianças.

Ao entrar em contato com a bibliografia relacionada ao trabalho com instituições, assim como a relacionada à educação, observa-se que o tema da mãe social é sempre abordado. Interessante mencionar, no entanto, a dificuldade de se encontrarem estudos brasileiros que visem a 
compreender a postura, o comportamento, assim como o papel dessa profissional na vida das crianças. Assim, ainda não é possível fazer afirmações quanto ao vínculo que se estabelece entre criança e mãe social e o papel desse vínculo na construção da subjetividade da criança.

Uma hipótese a ser considerada, no caso de crianças sem contato com a família, seria a de que a mãe social acaba se tornando a referência de figura parental, uma vez que a criança passa a maior parte do tempo com ela quando está na instituição. Profissionais que atuam junto a crianças em situação de abandono não podem, entretanto, ser confundidos com mães ou professoras ${ }^{11,12,14}$. São profissionais responsáveis pelo cuidado e pela garantia da saúde psíquica de crianças extremamente fragilizadas em função de suas histórias de vida, e que necessitam do máximo de estabilidade e de qualidade no cuidado que recebem.

Como mencionado anteriormente, uma característica fundamental dos abrigos é a alta rotatividade dos profissionais que atuam nessa área. Mais precisamente, a alta rotatividade das mães sociais - fato que deve ser observado atentamente. Afinal, cada vez que uma mãe social vai embora, um novo vínculo é rompido, colocando a criança em contato com mais um abandono em sua história.

Nesse contexto, algumas questões acabam sendo inevitáveis: como admitirmos a alta rotatividade de profissionais que lidam diretamente com crianças que já sofreram um rompimento extremamente significativo em sua história e que deveriam ter a garantia de uma relação estável e, por que não, reparadora? Como fica a criança cada vez que uma mãe social vai embora? Como essa separação é trabalhada? Como se dá o novo vínculo? E, mais importante: como diminuir a rotatividade, uma vez que sabemos a importância da constância e da estrutura necessárias para que essas crianças possam se desenvolver de forma minimamente saudável?
Como afirma Justo ${ }^{15}$, "a circulação e alta rotatividade de pessoal, no interior dessas instituições, acaba expondo as crianças e intensificando suas experiências de perda, reeditando copiosamente a situação primeva de abandono e desamparo" (p. 84).

A cada mudança de mãe social, ocorre também mudança na rotina da realidade da criança. Ainda que a instituição tenha regras básicas a serem seguidas, as relações subjetivas variam, dependem de cada pessoa e, conseqüentemente, se dão de formas diferentes; os limites acabam variando, assim como a forma de contato, o afeto, para mencionar alguns pontos das relações interpessoais. Sendo assim, com a inconstância e rotatividade de profissionais, a quem cabe o papel de limitar e conter? ${ }^{16}$.

As questões aqui levantadas são de grande relevância ao pensarmos na realidade dos abrigos brasileiros. Afinal, quais as perspectivas dos indivíduos que crescem nessas instituições? Quais suas possibilidades?É possível garantir um desenvolvimento biopsicosocial, saudável, para essas crianças e adolescentes? A quem cabe a responsabilidade desse trabalho?

Ao se reconhecer a importância da estabilidade do ambiente, no sentido de contribuir para a reparação do sofrimento de crianças que, tão cedo, passaram por rompimentos, não se pode deixar de considerar que a qualidade do cuidado e do atendimento que receberão no abrigo será fundamental para a estruturação física e psíquica na vida dessas crianças.

As possibilidades de reparação e reestruturação estão diretamente ligadas ao trabalho desenvolvido pelas mães sociais, uma vez que são essas profissionais que passam a maior parte do tempo com as crianças, sendo responsáveis pelo seu dia-a-dia, por sua rotina, acompanhando-as diretamente em seu desenvolvimento, brincadeiras, interações. São elas que observam e estão em contato direto com as reações, comportamentos, demonstrações de angústia, ansiedade, alegria e dificuldades das 
crianças $^{17, \# \# . ~}$

Uma vez abandonadas, violentadas, desrespeitadas, essas crianças só podem se estruturar novamente se o ambiente onde se encontram garantir que isso seja possível. Para tanto, pensamos que as instituições responsáveis devam se organizar e se estruturar de forma a atender às necessidades das crianças.

\section{O MÉTODO}

A relevância da pesquisa qualitativa reside no fato de se colocar em evidência a essência dos eventos ${ }^{18}$. Ou seja, prioriza-se a intensidade dos fenômenos, em função de seu caráter essencialmente complexo. Deste modo, pode-se alcançar uma interpretação mais profunda e cautelosa de aspectos simbólicos que podem, inclusive, incluir o silêncio e o não-dito. Assim, torna-se possível a compreensão da dimensão subjetiva de fenômenos complexos.

Esta pesquisa teve como proposta trabalhar com observações da dinâmica das casas lares na instituição, mantendo como foco principal a relação mãe social - criança. A partir dessas observações, buscamos entender melhor o contexto das relações estabelecidas na dinâmica institucional, através dos momentos de cuidado e de interação entre adultos e crianças. Fizemos uso da observação participante, proposta pelo método etnográfico de pesquisa metodologia utilizada pela antropologia, mas que teve grande contribuição neste trabalho ${ }^{19}$.

\section{$O$ contexto}

Escolhemos, para observação, uma instituição que recebe crianças no período de zero a três anos. As crianças podem permanecer na instituição até a maioridade, mas sua chegada só pode se dar no período mencionado. Após apresentação do projeto de pesquisa à direção da instituição, bem como seu consentimento, entramos em contato com Rosa, a mãe social da Casa Branca - objeto de nosso estudo. Esta mãe social trabalha na instituição há 13 anos.

Esta instituição funciona de acordo com o modelo de casas-lares, dispondo de cinco casas que abrigam, em média, 14 crianças cada uma. Estas crianças são atendidas por um casal social e uma mãe social substituta, sendo que, em alguns casos, a casa pode ter somente a mãe social e a mãe social substituta.

\section{Os sujeitos}

A casa escolhida para a coleta de informações é conhecida como Casa Branca e contava com uma mãe social, Rosa, de 43 anos, e Ana, a mãe substituta da casa. A Casa Branca contava com 12 crianças e 4 adolescentes, sendo um deles filho biológico de Rosa. As crianças e adolescentes sob a responsabilidade de Rosa eram: Raquel (3 anos), Leandro (3 anos), Luís Paulo (3 anos), Valéria (2 anos), Andréa ( 2 anos), Estela (2 anos), Beatriz (1 ano), Júlia (1 ano), Cláudio (2 anos), José (7 meses), Fábio (3 anos), Tiago (11 meses), Brena (16 anos), Jamil (17 anos), Dário (13 anos), William (13 anos - filho biológico de Rosa) (Todos os nomes são fictícios).

A Casa Branca é composta por quatro quartos, dois dos quais são ocupados pelas crianças menores, sendo o terceiro ocupado pelos adolescentes da casa, com exceção do filho biológico da mãe social, que, no período das observações, dormia com ela em seu quarto. A casa tem uma cozinha ampla, uma sala de jantar e estar e uma sala de televisão. Existem móveis apropriados para cada ambiente, os quartos são amplos e bem organizados. Ob-

\footnotetext{
Nogueira PC, Pereira JMF. A mãe e as mães: maternidade ou maternidades? Manuscrito não publicado. Brasília: Universidade de Brasília; 2002.
} 
servam-se bichinhos de pelúcia nas camas. $\mathrm{Na}$ sala de televisão tem um armário, no qual são guardados gibis. Além disso, no corredor existe uma pequena prateleira suspensa no alto, na qual ficam alguns brinquedos.

\section{Instrumento}

Para justificar a escolha da etnografia como um dos métodos utilizados para a coleta de dados desta pesquisa, seria interessante resgatar Marin ${ }^{16}$, ao afirmar que um caminho fiel para estudar a presente realidade é captar a instituição em seu cotidiano, "abrangendo a relação das pessoas entre si, a sua rotina, acompanhar os adultos em seu trabalho e as crianças em suas atividades e situações naturais" (p.69).

A etnometodologia tem como objetivo entender como as atividades do dia-a-dia dos indivíduos podem constituir métodos capazes de analisar as ações práticas, as circunstâncias, o conhecimento baseado no senso comum sobre as estruturas sociais e o raciocínio sociológico prático, assim como de entender suas propriedades formais vistas e observadas dentro do próprio ambiente. Haguette ${ }^{19}$ afirma que a etnologia busca descobrir os "métodos" usados pelas pessoas em sua vida cotidiana e em sociedade para que construam sua realidade social. Além disso, tal método busca também "descobrir a natureza da realidade que elas constroem" (p. 50). A autora menciona ainda que a etnometodologia não tem como objetivo a correção ou modificação do ambiente - estes não são os objetivos destes estudos, assim como não o é a busca de teorização.

\section{PROCEDIMENTOS}

A primeira observação deu-se em 17 de julho de 2003, no período da manhã. A observação teve como foco a rotina interna das cri- anças na casa, seguida do almoço, no refeitório. O período total de observação foi de três horas. A segunda ocorreu em 22 de julho, no período da tarde e teve como foco a observação do banho e do momento do Evangelho atividade que ocorre uma vez por semana com a coordenadora pedagógica da instituição. A terceira observação ocorreu no dia 24 de julho e teve duração de duas horas, período no qual observei o banho e o momento do lanche das crianças na própria casa.

Uma segunda etapa de observações deuse me dezembro do mesmo ano. Em 11 de dezembro, no período da tarde, observamos as crianças ainda na casa, antes de irem para a quadra, seguida de uma observação do período em que passaram na quadra. O tempo total foi de 3 horas. A próxima observação ocorreu no dia 13 de dezembro, pela manhã, tendo duração de três horas. Observamos a rotina interna da casa, seguida do almoço no refeitório. Finalmente, no dia 16 de dezembro, pudemos observar o momento que se segue ao almoço das crianças, período no qual a mãe social coloca algumas para dormir.

\section{MÉTODO DE ANÁLISE}

A análise dos dados obtidos, a partir da observação participante, foi feita com base na proposta de Minayo $^{20}$, na qual a autora sugere que o pesquisador faça uma leitura exaustiva e repetida dos textos, estabelecendo uma relação interrogativa com este exercício que pode ser denominado de "leitura flutuante". Dessa forma, podem ser buscadas relações dialéticas entre as categorias empíricas e as categorias analíticas. Em seguida, Minayo ${ }^{20}$ propõe que se faça uma leitura denominada de "transversal" (p. 236) de cada corpo de dados obtidos, para então se fazer um recorte destes dados em "unidades de registro" (236), sendo estas referenciadas por temas. 


\section{DISCUSSÃO DOS RESULTADOS}

\section{As pequenas violências}

Através das observações, pudemos constatar a existência de um tipo de tratamento que denominamos "pequenas violências". Apesar de não constatarmos nenhum tipo de violência física, em alguns momentos era possível notar um desrespeito do adulto para com a criança, suas ações e sentimentos. Desrespeito caracterizado não só pelo contato físico, mas fundamentalmente pela forma de se falar com elas, nos comentários a respeito dos comportamentos, das reações, assim como das histórias de vida. Durning ${ }^{21}$ define estes comportamentos como violências "banais e ordinárias" (p.77). Com relação aos significados desse tipo de comportamento, Rapoport ${ }^{22}$ afirma que, em si, a palavra "violência" pode, certamente, soar como algo chocante, mas ainda assim, é reveladora de todas as violências psicológicas que um adulto cheio de boa vontade pode provocar nas crianças, ainda que sem sabê-lo.

Essas "pequenas violências" aparecem de forma sutil, ficam "escondidas", misturadas à rapidez da rotina institucional e suas exigências, e passam, muitas vezes, despercebidas. Violências marcadas, muitas vezes, não pela ação do adulto, mas, ao contrário, pela falta dessa, ao ignorar e desconsiderar as necessidades e manifestações das crianças.

Ao observar a reação da mãe social nos momentos em que as crianças choravam, pudemos perceber uma dificuldade de acolhimento e legitimação do sofrimento, marcada por uma atitude de desrespeito e desconsideração. Em diferentes momentos, o choro foi tratado como algo sem valor e sem importância, associado a adjetivos que caracterizavam as crianças de forma negativa, como pode ser constatado nos trechos descritos a seguir.

\footnotetext{
“Essa Beatriz é uma escandalosa,
}

olha!; Essa Vanessa é manhosa! Xiiii! Tá bom, manhosa!; Cadê as lágrimas, Valéria?" (Falas da mãe social).

Beatriz continua no carrinho dando sinais de incômodo e tédio. Valéria começa a empurrá-lo, brincando com Beatriz. Rosa a retira de forma brusca, sentando-a violentamente no sofá. A criança chora e a mãe social manda-a parar. (Relato de observação da rotina).

O comportamento da mãe social em relação às manifestações de sofrimento ilustra a dificuldade presente na prática de adultos responsáveis pelo cuidado de crianças separadas de suas famílias, como descrito por Appell ${ }^{23}$, Bosse-Platière et al. ${ }^{24} \mathrm{e}$ Golse ${ }^{2}$. A desconsideração do sofrimento e da angústia já é, em si mesma grave e deve ser considerada como algo nocivo à criança. Não se pode, entretanto, esquecer o histórico e a realidade de crianças que são ainda extremamente jovens. Crianças que, como afirma Appell ${ }^{25}$, deveriam estar vivendo uma relação simbiótica com a mãe, pois são bebês em plena elaboração das relações objetais, bruscamente rompidas e, frequientemente, já perturbadas.

Appell ${ }^{23}$ lembra que essas crianças se encontram no período pré-verbal, algumas em fase de início da utilização da linguagem. "Sua vulnerabilidade em função da separação e de uma situação de carência está em seu grau máximo e a institucionalização representa um alto risco para a sua saúde mental" (p. 43). A questão da idade das crianças é também crucial para os adultos, que devem se confrontar com reações extremamente fortes provocadas pelo contato com bebês. "Acolher estas crianças, entrar em contato com elas, nutrir uma relação significativa, constitui uma situação bem específica, totalmente diferente daquela que surge no contato com crianças mais velhas" (p. 43).

Deste modo, quando se pensa sobre o histórico, assim como sobre as necessidades 
de crianças em situação de abrigamento, devese considerar como sendo um tipo de violência o tratamento que ignora e diminui as manifestações de sofrimento, representadas pelo choro - comunicação comum em crianças em fase pré-verbal.

Ao entrar em contato com reflexões de autores que vêm estudando o tema da relação adulto-criança, mais especificamente no contexto institucional, pode-se compreender as reações da mãe social em relação ao comportamento de angústia das crianças. Appell ${ }^{23}$ ressalta que o comportamento de se transferir de uma criança para outra, oferecendo cuidados rápidos e impessoais, mantendo-se afastada das crianças entre um cuidado e outro, garante o distanciamento que protege o adulto. Ou seja, evita-se, assim, o contato com os sentimentos da criança e, conseqüentemente, com seus próprios sentimentos.

Dentre os sentimentos mais freqüentes que surgem nos cuidadores estão: a falta de ânimo e a vontade de fugir, além de cólera e hostilidade.

"Como é doloroso descobrir tais sentimentos em si em relação às crianças, o adulto tende a se proteger, usando de todos os meios possíveis, como, por exemplo, rejeitando ou ignorando crianças cujos problemas colocam os profissionais em contato com os próprios sentimentos, fazendo-os manterem-se próximos daquelas crianças com as quais eles se sentem melhor" (Appell ${ }^{23}$, p. 45).

Tais comportamentos ficam evidentes nas observações de Rosa: a mãe social mantém-se ocupada nas atividades que envolvem o atendimento, indo de uma criança a outra sem tempo para interações mais prolongadas, sem tempo para se ater às demandas individuais.

\section{As agressões verbais}

Ao longo das observações, pudemos perceber que, além da dificuldade de lidar com o choro, a mãe social tinha uma atitude agressiva em relação às crianças, usando de adjetivos e comentários que as desqualificavam e que serviam para, mais uma vez, banalizar o sofrimento.

“Eca, Valéria! Toda cagada! Porcona! Cagando na roupa? Você, hein?; Não tem vergonha não, Andréia? Cagando na roupa?; Fez cocô? Sua cagona!; Essa menina, tudo o que ela pega é pra destruir; Eh, Raquel... Essa Raquel é enjoada!; Essa Beatriz é escandalosa, olha!" Falas da mãe-social).

Appell $^{23}$ ressalta que este tipo de reação é comum em profissionais que trabalham com crianças com histórico de abandono. Na presença de afinidade entre o profissional e a criança, esse desenvolverá uma atitude mais cuidadosa em relação àquela que recebe seus cuidados. Do contrário, se nenhuma afinidade aparece, não tarda a se estabelecer uma relação extremamente negativa, caracterizada por culpabilizações recorrentes em relação às crianças, descritas como sendo "muito isso ou muito aquilo" (p. 44), decepcionando os profissionais. Para a autora, estabelece-se, então, uma total aversão por parte dos cuidadores, que acabam se sentindo culpados, dificultando ainda mais o contato.

Autores como Appel $^{23}$ e David $^{+}$ressaltam que o contato com a criança em situação de abandono pode evocar sentimentos negativos naquele que cuida. A falta de investimento afetivo dos pais, o histórico de abandono, a realidade da vida na instituição que limita as trocas de afeto, contribuem para que as crianças tenham uma aparência ruim, denunciando a fal-

\footnotetext{
David M. Du corporel au psychique. Que le bébé reste acteur de son développement. Soins protecteurs e thérapeu tiques au quotidien dans l'accueil du jeune enfant. Palestra de abertura. Budapeste: Symposium Europeu de Budap este; janeiro 1996.
} 
ta de investimento afetivo e, consequientemente, a carência que sofrem. Além disso, são crianças que demandam muito de quem cuida, exigindo do profissional uma disponibilidade que, em função do ritmo institucional, ele não tem ${ }^{4,+}$. Deste modo, na tentativa de se proteger e se manter afastada destes sentimentos e de toda a complexidade envolvida neste trabalho, a mãe social agride, desconsidera e, conseqüentemente, mantém uma distância que a protege.

Deve-se mencionar, ainda, a dificuldade relacionada às emoções que surgem no contato com crianças pequenas, suscitadas em função da maternidade latente presente nas mulheres que delas se ocupam - questão que se torna ainda mais complexa e confusa quando se trata de mães-sociais que têm seus próprios filhos, como no caso de Rosa. Deve-se levar em conta que muitas dessas projeções suscitadas no contato com as crianças (e que estão relacionadas à maternidade latente) ficam, muitas vezes, como menciona David"25 "em surdina" (p.23), uma vez que não encontram espaço para serem expostas, discutidas e elaboradas. Sendo assim, pode-se pensar que as situações de violência verbal, de desconsideração e desrespeito às crianças podem ter relação com a falta de uma definição do papel da mãe social que é, em sua essência, extremamente confuso e complexo, gerando defesas que podem aparecer na forma de afastamento das crianças ou mesmo de agressão verbal, como pôde ser constatado nas observações.

Outro ponto importante refere-se à carga de trabalho de Rosa, ao ter que responder às necessidades individuais de tantas crianças necessidades relacionadas a questões de ordem prática, como higiene e alimentação, além de necessidades afetivas e emocionais. Sabe-se que crianças muito pequenas exigem grande carga de afeto, de atenção e de energia. Ao tratar de crianças com histórico de abandono, deve-se pensar que esta carga torna-se ainda maior, exigindo do adulto uma disponibilidade que pode estar além de suas possibilidades em função do número de crianças, da carga de trabalho, assim como da falta de preparo para exercer tal função.

Finalmente, um outro ponto refere-se às questões relacionadas à separação, se levarmos em conta o caráter temporário da instituição. Ou seja, pode-se entender o comportamento agressivo da mãe social como uma forma de defesa e de afastamento em relação às crianças, que cedo ou tarde retornarão às suas famílias de origem, serão adotadas ou partirão, ao completar 18 anos.

A partir destes pequenos episódios, pode-se compreender a complexidade deste trabalho. Neste sentido, David ${ }^{25}$ afirma que:

(...) foi necessário muito tempo para se admitir que o acolhimento destas crianças não é nem simples, nem um remédio, para se descobrir a natureza destas dificuldades e a origem da complexidade e constatar que elas formam uma síndrome constituída de problemas que estão na origem da separação, síndrome denominada de 'mal do acolhimento' (grifos da autora, p. 27).

A dificuldade da mãe social, no sentido de garantir cuidados de qualidade, assim como suas reações frente às demonstrações de angústia e desconforto das crianças colocam em evidência o "mal do acolhimento" proposto por David $^{25}$. Neste sentido, Appell ${ }^{23}$ afirma que os cuidadores sem supervisão e orientação correm sérios riscos, em função da exposição às emoções provocadas pelo contato com crianças pequenas e em sofrimento. Ademais, segundo David ${ }^{25}$ essas crianças trazem, em seu comportamento, as marcas do sofrimento causado pela separação de sua família de origem,

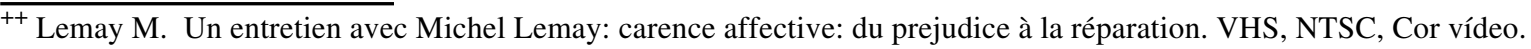
Collection parole donnée; 1995.
} 
introduzindo, na relação com quem as acolhe, o que interiorizaram da experiência anterior. $\mathrm{Ou}$ seja, ligações frágeis, muitas vezes patológicas, tecidas na relação com os pais, acabam se reproduzindo na relação criança - família temporária (neste caso, representada somente pela mãe social). Tal relação é, segundo a autora, marcada por características como fusão, falta de estimulação ou rejeição e maus tratos.

\section{A limitação dos movimentos e da brincadeira}

Ao longo da transcrição das observações, foi possível encontrar comentários pessoais das pesquisadoras, que descreviam sentimentos e sensações que foram emergindo no contato com a realidade das crianças. Aparecem descrições de cansaço e ansiedade. Tais sentimentos apareciam ao longo da transcrição das observações das crianças que passavam muitas horas presas nos carrinhos ou sentadas no sofá, sem poder levantar e se movimentar pela sala. Foi possível observar um constante racionamento de brinquedos. As crianças disputavam os poucos objetos que circulavam pela sala, como gibis ou até mesmo páginas soltas, além de pequenos brinquedos que passavam de mão em mão, gerando conflitos e disputas que eram freqüentemente reprimidos por Rosa, que retirava e guardava os objetos, causando frustração e mais agressividade.

Nos diferentes momentos em que tivemos contato com o dia-a-dia da casa, somente em um dia foi possível observar as crianças brincando livremente. Ainda assim, Rosa fez intervenções durante toda a atividade (que teve duração de dez minutos), limitando o espaço da brincadeira, que foi finalizada bruscamente.

Uma criança que está no carrinho começa a chorar, dando sinais de tédio e incômodo. Rosa grita: "Pára de choro, Beatriz!"”. Nesse momento, as crianças que estão no carrinho tentam sair e são rapidamente re- primidas pela mãe social. Uma das crianças encontra-se no carrinho desde o início da observação (permaneceu sentada no carrinho por uma hora e quarenta e cinco minutos, e durante todo o almoço). Após $50 \mathrm{mi}$ nutos de observação, o sentimento é de cansaço, pouca energia e vontade de ir embora. As crianças se agitam em torno da observadora, sentam-se ao seu lado, tentam pegar sua caneta, sua bolsa, e demandam atenção e afeto. (Relato de observação feita na sala da casa).

Rosa entra na sala com uma caixa de peças de montar, tipo 'Lego'. Os olhos das crianças brilham ao verem a caixa de brinquedos, elas se agitam e começam a rodear a caixa, que se encontra ainda nas mãos da mãe social. Esta dá um grito, dizendo: 'Calma!'. Rosa senta-se no chão com eles e abre a caixa. As crianças começam a retirar os brinquedos e a montá-los. Rosa monta junto com eles e, de vez em quando, dá umas broncas, dizendo que não precisam brigar. Uma criança coloca algumas peças na caixa e a mãe social derruba os brinquedos de volta, dizendo que não é hora de guardá-los e sim que é hora de brincar. Outra criança espalha os brinquedos pela sala e Rosa dá um grito, dizendo que não é para espalhar, mas para brincar. Algumas crianças sobem no sofá e Rosa grita, dizendo que é para descerem. Parece que a regra é que todos devem ficar no chão, brincando com aquilo que ela propôs. Rosa ajuda uma dupla de crianças com uma montagem e elas continuam, demonstrando interesse e criatividade. Este é o único momento em que as crianças realmente se concentram, montando diferentes formas com as peças e interagindo entre si. Depois de exatamente dez minutos, entretanto, Rosa pega a caixa e manda as crianças guardarem tudo de volta. Elas obedecem prontamente e desmontam as grandes peças que haviam construído para colocar na cai- 
xa. Rosa permanece sentada no sofá, observando as crianças. Apesar de não resistirem à ordem de guardar os brinquedos, após terminar, as crianças se agitam pela sala, gritando e se movimentando." (Relato de observação feita durante a brincadeira livre).

Vitor é empurrado por uma criança de outra casa e cai, cortando a boca, que começa a sangrar. Ele chora muito e Joana (a mãe social substituta) levanta-o de forma brusca, limpando sua boca com uma fralda, sem olhar ou conversar com ele. Ele permanece chorando por um longo período. $\mathrm{Ne}$ nhum adulto se aproxima para atendê-lo. Joana se aproxima novamente e retira a mão dele da boca.; enquanto isso, Raquel, Júlia e Beatriz permanecem o tempo todo nos carrinhos e ninguém se dirige a elas. (Relato de observação feita na quadra de esportes).

Durante a observação da brincadeira, pudemos notar que esse momento parece não ter um significado para a mãe social e, conseqüentemente, acaba não sendo valorizado. Tratado como parte da rotina institucional, começa e termina sem preparo, sem que se observe o que as crianças fazem e constroem enquanto brincam, sendo elas interrompidas e reprimidas o tempo todo, ficando limitadas a tempo, espaço e objetos restritos.

Winnicott ${ }^{26}$ discute a função dos momentos de interação entre adulto e criança e sua relação com a capacidade da criança manifestar-se através da brincadeira.

"Um bebê pode ser alimentado sem amor, mas um manejo sem amor, ou impessoal, fracassa em fazer do indivíduo uma criança humana nova e autônoma. Onde há confiança e fidedignidade há também um espaço potencial, espaço que pode tornar-se uma área infinita de separação, e o bebê, a criança, o adolescente e o adulto podem preenchê-la criativamente com o brincar, que, com o tempo, se transforma na fruição da herança cultural" (p. 150).

\section{CONSIDERAÇÕES FINAIS}

Dentre as necessidades primordiais de crianças com um passado de ruptura e de sofrimento, está a possibilidade de encontrarem ambiente adequado, atmosfera que as ajude a encontrar segurança e bem-estar, um quadro não somente acolhedor, mas também estável. Para tanto, é necessário, como propõem David et al. ${ }^{27}$, que se possa oferecer a elas uma vida cotidiana rica. Apesar do caráter transitório da instituição, seu papel não deve se restringir a ser um ambiente no qual a criança passe o tempo, à espera de uma outra solução para sua vida, mas é fundamental que o abrigo exerça uma função terapêutica. A qualidade do cuidado, associada a um espaço no qual a criança possa explorar, manipular, movimentar-se, experimentar, (tudo isso através da brincadeira) é fundamen$\operatorname{tal}^{28-30}$.

Questionamos, então, as possibilidades de desenvolvimento rico e saudável de crianças que passam horas seguidas no carrinho ou sentadas no sofá. São crianças que já andam, engatinham, têm energia e necessidade de movimentar-se, mas ficam presas, com seus movimentos e manifestações limitados, sem brinquedos e com possibilidades de interação restritas ou até mesmo nulas. Em diversos momentos, pudemos constatar o olhar de apatia e insatisfação das crianças que, muitas vezes, se mexiam e levantavam dos carrinhos, na tentativa frustrada de sair, desistindo e adotando uma posição passiva e apática logo em seguida.

Para que possa propiciar uma forma de existência adequada e saudável à criança que depende e se apóia no adulto, é fundamental que este esteja capacitado para observá-la, estando atento às necessidades individuais de cada um. Reside aí a dificuldade estrutural da realidade observada. Apesar de atender às necessidades básicas de cada criança, mantendo-as limpas, alimentadas e bem arrumadas, a mãe social não consegue identificar as necessidades 
particulares de cada uma - atitude que só pode existir com o suporte de treinamento, preparo, supervisão e, fundamentalmente, a partir da definição de seu papel como profissional do cuidado $^{23,31,32}$.

Nessa realidade em que as imprecisões e confusões de papéis imperam, observa-se uma tentativa de controle por parte do adulto. Deste modo, a repressão e limitação dos movimentos têm origem na necessidade de controlar qualquer tipo de manifestação proveniente das crianças, em uma tentativa de assegurar o controle em seus aspectos mais variados: a aparência física, a limpeza, os movimentos, as brincadeiras, as conversas, as manifestações de angústia ou incômodo.

Ao discutir a relação estreita entre cuidados adequados e a possibilidade de desenvolvimento e da capacidade exploratória da criança, David ${ }^{12}$ discorre sobre a importância da qualidade dos cuidados oferecidos à criança, cuidados que podem garantir a saúde do bebê, mas que também alimentam seu narcisismo primário, colocando-o em um estado de conforto ao oferecer-lhe prazer e alegria, ajudando-o a sentir-se bem em sua pele e em seu corpo fatores que contribuem para sua propensão natural de ser ativo. Sendo assim, a atividade espontânea livre do bebê tem relação estreita com os cuidados que recebe. Compreende-se, então, que a qualidade do desenvolvimento da atividade livre depende do tempo e da qualidade dos cuidados recebidos da cuidadora, sendo esses dois aspectos fundamentais e complementares.

David" afirma que "a sensibilidade e a atividade corporal são ferramentas preciosas das quais o bebê dispõe, uma vez que ele ainda não possui a linguagem verbal" (p.48). Essas ferramentas têm função fundamental, pois é através delas que o bebê pode "sentir, perceber, reagir, se exprimir, comunicar, explorar, experimentar, fazer e refazer e, conseqüentemente, antecipar e pensar" (p. 49). Assim, a atividade livre es- pontânea do bebê contribui para a elaboração das emoções, constituindo um tempo de interiorização, de integração, e essa experiência vivida por "um" (o bebê) é complemento precioso da experiência emocional "a dois" (bebê e cuidadora) no âmbito da constituição do self (p. 48).

David et al. ${ }^{27}$ propõem a existência de alguns aspectos fundamentais, que envolvem segurança afetiva, ou seja, o estabelecimento e sustentação de relações interpessoais estáveis, contínuas, íntimas e calorosas entre crianças e um número restrito de adultos. Além disso, discutem a importância do respeito e sustentação indireta da atividade livre espontânea. Tais aspectos propiciam uma aspiração constante, por parte do adulto, de que cada criança possa ter uma boa percepção de si e, a partir do seu estágio de desenvolvimento, adquira consciência de si mesma, situando-se em seu ambiente social e material, no espaço e no tempo, nos eventos e nas relações que lhe dizem respeito, em sua história pessoal e familiar, no presente, no passado, assim como no futuro imediato ou distante. Para as autoras, a busca e manutenção de um bom estado de saúde mental, assim como do bem-estar corporal da criança, só pode ser garantida se baseada na satisfação das necessidades anteriormente mencionadas. Esses autores ressaltam que a busca constante da satisfação das necessidades da criança deve determinar o projeto educativo e a atitude pedagógica da instituição, a fim de que a criança possa sentir-se, todo o tempo, "uma pessoa acompanhada e sustentada, sujeito participante, parte ativa e não objeto manipulado ou dirigido" (p. 139).

Sendo assim, a possibilidade de uma intervenção em um abrigo se daria no âmbito da formação dos profissionais, mais especificamente, na capacitação das mães sociais. Essa qualificação deveria implicar questionamento e definição dos papéis, no sentido de preparar as profissionais para o oferecimento de cuidados 
adequados, de qualidade, que considerem as crianças, sujeitos ativos, dignos de atenção, observação e respeito. Tudo isso sem, no entanto, se propor a serem mães - espaço que deve ficar em aberto, considerando as possibilidades futuras da criança: adoção, reintegração familiar, colocação em família substituta.

Além disso, quando se observa a carga física e emocional dessa profissão, é inegável a necessidade de suporte, de reuniões, de supervisões constantes, com o objetivo de oferecer um espaço para a fala, a dúvida, o questionamento, as trocas de informação e experiência. Do contrário, observa-se a perpetuação das chamadas violências institucionais, que contribuem para o surgimento de maus tratos endêmicos, representados por negligência, abandono, falta de estimulação ${ }^{22}$ - comportamentos que puderam ser observados na realidade estudada.

Nesse sentido, como afirma Pereira ${ }^{18}$, é somente a partir da capacitação profissional que as mães sociais poderão assumir posição de maior autonomia na educação da criança e do adolescente, sendo reconhecidas como figuras de referência, tanto para a criança, como no que se refere aos conhecimentos que têm sobre ela.

\begin{abstract}
This article intends to reflect the reality of children who are temporarily living in orphanages. The objective is to understand the role of the caretaker in charge of the children in this context. A qualitative research was developed in an institution that receives and takes care of children from birth to three years old. All the children are under the responsibility of a social mother. The "home" analyzed in the study was responsible for the care of twelve children and four adolescents (one of them being the biological child of the social mother). The study conducted a total of six observations utilizing etnomethodology, which focused on the social mother caring routines involving physical care, playing periods, feeding and going to bed. The observations led the researchers to conclude that a social mothers background qualifications are the most important aspect to be observed if we consider the importance of adequate care offered to children who have been living in orphanages, as a result of being of previous abandoned.
\end{abstract}

Key words: Institutionalized child. Orphanage. Social mother.

\section{REFERÊNCIAS}

1. Eliacheff C. Corpos que gritam. São Paulo: Ática; 1995.

2. Golse B. Sobre a psicoterapia pais-bebê: narratividade, filiação e transmissão. São Paulo: Casa do Psicólogo; 2003.

3. Winnicott DW. O ambiente e os processos de maturação. Trad. I. C. S. Ortiz. Porto Alegre: Artes Médicas; 1990

4. Winnicott DW. Os bebês e suas mães. Trad.J. L. Camargo. São Paulo: Martins Fontes; 1999.

5. Winnicott DW. Da pediatria à psicanálise:obras escolhidas. Trad D. Bogomoletz.. Rio de Janeiro: Imago, 2000.

6. Bowlby J. Formação e rompimento dos laços afetivos. Trad.A. Cabral São Paulo: Martins Fontes; 2001.

7. Bowlby J. Apego:a natureza do vínculo Trad. A
Cabral. São Paulo: Martins Fontes; 2002. v.1.

8. Spitz R. O primeiro ano de vida. Trad. E. M. B. Rocha. São Paulo: Martins Fontes; 2000.

9. Weber LND, Kossobudzki LHM. Filhos da solidão: institucionalização, abandono e adoção. Curitiba: Governo do Estado do Paraná; 1996.

10. Bosse-Platière $\mathrm{S}$. Les maternités professionnelles. Toulouse: Érès; 1989.

11. David M. La parole est aux soignantes! In: David M. Organizador. Le bébé, ses parents, leurs soignantes. Ramonville Saint-Agne: Èrés; 2001. p. 11-24

12. David M. Pour une meilleure connaissance dubébé. Contributions de l'Institute Emmi-Pikler. In: Szanto-Feder A. Organizador. Lóczy: un nouveau paradigme? L'institute Pikler à facettes multiples. Paris: Presses Universitaires de France; 2002. p. 32-50.

13. Winnicott DW. Privação e delinqüência. Trad. A. 
Cabral. São Paulo: Martins Fontes; 1999.

14. Golse B. Les très jeunes enfants en institution: un paradigme pour les psychanalystes. In: Szan to-Feder A. Organizador. Lóczy: Un nouveau paradigme? L'institute Pikler à facettes multiples. Paris: Presses Universitaires de France; 2002. p. 23-29.

15. Justo JS. A institucionalização vivida pela criança de orfanato. In: Merisse A, Justo J S, Rocha LCd, Vasconcelos MS.Organizadores. Lugares da infância: reflexões sobre a história da criança na fábrica, creche e orfanato. São Paulo: Arte \& Ciência; 1997. p. 71-92.

16. Marin ISK. Febem, família, identidade: o lugar do outro. São Paulo: Escuta; 1999.

17. Pereira JMF A adoção tardia frente aos desafios na garantia do direito à convivência familiar Brasília (DF) ;2003. [Dissertação de Mestrado - Instituto de Psicologia da Universidade de Brasília]

18. Demo P. Pesquisa e informação qualitativa: aportes metodológicos. Campinas: Papirus; 2001.

19. Haguette MTF. Metodologias qualitativas na sociologia. Petrópolis: Vozes; 2000.

20. Minayo MCS. O desafio do conhecimento: pesquisa qualitativa em saúde. São Paulo: HucitecAbrasco; 1992.

21. Durning P. Toute institution accueillant et soignantdes enfants est-elle potentiellement mal traitante? In: Gabel M, Jésu F, Manciaux M. Organizadores. Maltratainces institutionnelles: accueillir et soigner les enfants sans les maltraiter Paris: Éditions Fleurus; 1998. p. 71-86.

22. Rapoport D. Du depot à l'accueil: vers des pouponnières différentes? In: Dolto $\mathrm{F}$, Rapoport $\mathrm{D}$, This B. Organizadores. Enfants en souffrance. Paris: Stock Laurence Pernoud; 1981. p. 51-79.

23. Appell G. L'érradication de la carence en collectivité. Risques encourus par les soignants de je unes enfants séparés de leus famille. In: Soulé M.
Organizador. Les soignants à risques dans les interactions en faveur de la petite enfance Paris: ESF; 1986. p. 43-59.

24. Bosse-Platière S, Dethier A, Fleury C, Pasquier NL. Accueillir le jeune enfant: quelle professinal isation? Ramonville Saint-Agne: Érès; 1995.

25. David M Institutions pour bébés: un bien, un mal? In: Delion P. Organizador. Le bébé et ses institutions Ramonville Saint-Agne: Èrés; 2001. p.7-15.

26. Winnicott DW. O brincar e a realidade. Trad.J. O. A. A. Abreu e V. Nobre . Rio de Janeiro: Imago; 1975.

27. David M, Falk J, Tardos A. Le bébé en souf france: accueil, soins thérapeutiques. In: Appell G, Tardos A. Organizadores. Prendre soin d'un jeune enfant. Ramonville Saint-Agne: Érès; 1998. p. $129-158$

28. Pikler E. Se mouvoir en liberté dès le premier âge. Trad. A. Szanto Vendôme: Presses Universitaires de France; 1978.

29. Pikler E. Importance du mouvement dans le de veloppement de la personalité. Med Infantil 1984; 91 A(3): 273-8.

30. Tardos A, David M. De la valeur de l'activité libre du bébé dans l'elaboration du self. Devenir 1991; 3 (1): 9-33.

31. Fleury C. Muriel, Tünde et quelques réflexions sur le soin thérapeutique et l'attitude profession nelle. In: Clerget J. Organizador. L'accueil des toutpetits Ramonville Saint-Agne: Erès; 1998. p.6985.

32. Tardos A. L'observation du nourrisson par la mère ou son substitute et ses effets sur l'image qu'ils se font de l'enfant ainsi que, ce qui s'ensuit, sur leurs attitudes. In: Szanto A. Organizador. Lóczy: Un nouveau paradigme? L'institute Pikler à facettes multiplesParis: Presses Universitaires de France; 2002. p. 61-71. 